\title{
Predominance of G9P[4] Rotavirus from Children with Acute Gastroenteritis in Northwestern Mexico
}

\author{
Leticia Felix-Valenzuela ${ }^{a}$ Dora Patricia Cooley-García ${ }^{a}$ \\ Manuel Alberto Cano-Rangel ${ }^{\mathrm{b}}$ Maria de los Angeles Durazo-Arvizu ${ }^{\mathrm{b}}$ \\ Veronica Mata-Haro ${ }^{a}$ \\ ${ }^{a}$ Centro de Investigación en Alimentación y Desarrollo, AC, and ${ }^{b}$ Hospital Infantil del Estado de Sonora, \\ Hermosillo, Mexico
}

\section{Keywords}

Rotavirus G9P[4] · Genotyping · Gastroenteritis

\begin{abstract}
In Mexico, group A rotavirus (RVA) infections remain the most common cause of severe dehydrating diarrhea in children. This study was conducted to examine the circulating RVA strains in the northwest region of Mexico. RVA strains collected from stool samples of children were genotyped, and their partial sequences were analyzed. RT-PCR of the VP4 and VP7 genes showed the partial G9P[4] genotype in all the samples. Sequencing and phylogenetic analysis of the partial VP7 gene amplicons of 10 strains showed that they clustered in the RVA G9 lineage III, and 7 of them showed $100 \%$ identity with the reference strain LB1562, which was collected in the USA 2 years earlier. The amino acid sequences of the VP7 and VP4 antigenic regions were highly conserved between the analyzed RVA strains. Active surveillance is important for monitoring the emergence of RVA strains and their impact on cases of gastroenteritis.
\end{abstract}

(c) 2017 S. Karger AG, Basel

\section{KARGER}

(c) 2017 S. Karger AG, Base

0300-5526/17/0594-0228\$39.50/0

E-Mail karger@karger.com

www.karger.com/int
Group A rotavirus (RVA) remains the leading cause of severe diarrhea in children worldwide [1]. In Latin America, rotavirus caused an estimated 11,631 deaths in children $<5$ years of age in 2000 , and this number declined to 2,288 in 2013 , which is attributable to the introduction of vaccines [2].

RVA is a nonenveloped virus with a genome consisting of 11 segments of double-stranded RNA surrounded by a triple-layered capsid. The outermost capsid layer consists of 2 antigenic proteins: VP7 (glycoprotein) and VP4 (protease-sensitive protein). The genes coding for these proteins are the basis for the $\mathrm{G}$ and $\mathrm{P}$ dual genotyping system. To date, $27 \mathrm{G}$ and $37 \mathrm{P}$ genotypes have been identified, and at least $73 \mathrm{G} / \mathrm{P}$ combinations have been reported to infect humans $[3,4]$. Genotypes G1-G4 and G9 comprise $88.2 \%$ of the isolates globally. Currently, the most prevalent combinations are G1P [8], G2P [4], G3P [8], G4P [8], and G9P [8] [5], while others have reported the G12 genotype in combination with $\mathrm{P}[6]$ or $\mathrm{P}[8][6,7]$. Since the mid-1990s, there has been a global emergence of cases caused by genotype G9 strains, which were previously reported to represent $14.6 \%$ of isolations in Latin America and the Caribbean [8]. The rapid increase in RVA G9 strain cases with genetic heterogeneity has gen-

Veronica Mata-Haro

Centro de Investigación en Alimentación y Desarrollo, AC

Carretera a la Victoria $\mathrm{Km} 0.6$

Hermosillo 83304 (Mexico)

E-Mail vmata@ ciad.mx 
erated much interest in its origin and epidemiological significance [9]. In Mexico, few studies have reported the distribution and circulation of RVA genotypes. During the 1990s, the genotypes that were more frequently reported in the different states of Mexico were G3, G1, P[8], and $\mathrm{P}[4]$, and combinations thereof [10-12]. However, in recent years, genotype G9 has emerged, mostly in combination with genotype $\mathrm{P}$ [4] [13]. Since information of circulating genotypes is scarce in Northwestern Mexico, we report herein the genotype of strains causing diarrhea in children aged $<5$ years with acute gastroenteritis and diagnosed with RVA by antigen-detection immunoassay that were treated at the Children's Hospital of the State of Sonora (HIES) between February and March 2011.

In this study, 50 RVA-positive stool samples, as determined by the latex agglutination assay (Rotalex, Orion Diagnostica, Espoo, Finland), were subjected to seminested RT-PCR to determine their VP7 and VP4 (VP8*) genotypes using primers and procedures that were previously described [14-16]. Selected strains were used for sequencing, for which an 881-bp fragment (primers VP7$\mathrm{F}$ and VP7-R) of the VP7 gene and an 876-bp fragment (primers Con-2 and Con-3) of the VP4 gene were first amplified. Sequencing was performed by capillary electrophoresis (Macrogen, Seoul, South Korea), using primers VP7-R and Con-3 for VP7 and VP4 (VP8*), respectively. The sequences were analyzed using ChromasPro v1.5 software, and the web-based RotaC v2.0 (http:// rotac.regatool.be) was used to assign the genotype [17]. The sequences were deposited in GenBank (accession No. KX011580-589 for VP4, and KU244530-539 for VP7) and were compared with strains from different countries by aligning them using the CLUSTAL $\mathrm{W}$ program (BioEdit system version 7.2.5). A phylogenetic tree was constructed with MEGA6 software [18] using the maximum likelihood method based on the Kimura 2-parameter model (1,000 iterations for bootstrapping). The deduced amino acid sequences of VP7 and VP4 genes were obtained using MEGA6 software and were compared with sequences from other countries obtained from GenBank.

In this study, the genotype G9P[4] was detected in all the 50 samples; no mixed infections were detected. In Mexico, RVA genotyping studies in different geographical regions have identified circulating strains. For example, during 1994-1997, G1P [8] was the predominant genotype combination (40\%), followed by G3P [8] (19\%) and G2P[4] (16\%) [11]. The G9 genotype was first identified in the USA in 1983 and remained undetectable for approximately a decade. It reemerged in the mid-1990s, and due to the increased number of countries that have re-

G9P[4] Rotavirus in Northwestern Mexico ported G9, it has become the fifth most prevalent genotype globally [19]. In Mexico, G9 was detected between 1998 and 2001 in combination with genotype $P[6]$ and in cases of mixed infections of G1 + 9P[6+8] [20]. In 2010, the combination G9P[4] was identified in 23 states in Mexico [13, 21]. The G9P[4] genotype has also been reported in other countries in Latin-America since the 1990s [13].

Ten 641-bp sequences of the VP7 gene were analyzed and compared with reference strains obtained from GenBank. The phylogenetic tree (Fig. 1) showed that the 10 strains were grouped into a single cluster with the reference Mexican strain Mex1 157 and the USA strain LB1562. Seven of the 10 isolates (HM10, HM28, HM29, HM34, HM39, HM40, and HM45) showed 100\% identities with each other and the reference strains LB1562 and Mex1157, while the isolates HM13, HM46, and HM53 had 99.8\% identity with the other 7 isolates. The percentage of identity between the isolates in this study and the reference strains from other American countries ranged from 97.1\% (Canada) to 98.5\% (Argentina and Paraguay), and they grouped into the same cluster. At least 3 distinct lineages can be recognized from the phylogenetic analysis of the VP7 gene of the G9 strains [22]. In our study, phylogenetic analysis of the 641-bp partial VP7 gene showed that all strains were located in the lineage III cluster together with other strains from American countries (LB1562, Mex1157, BethesdaDC8, US1205/USA, Py02AP57/Paraguay, Arg2366/Argentina, R143/Brazil, and RT088-09/Canada). All of these strains are distinct from lineage II, with only $87.8-88.4 \%$ identity, and from lineage I, with $88.6-89.8 \%$ identity. Our results are consistent with other reports, which have shown that G9 strains isolated in the early 1990s or later from the USA and other countries are phylogenetically more related to each other than with the first strains isolated in the 1980s (lineage I) [23-25]. This observation has generated significant interest for determining whether new G9 variants evolved from the WI61 and F45 strains isolated in the USA and Japan in 1983 and 1985, respectively, or whether they represent an independent introduction of new strains of human or animal origin [23].

Ten 422-bp sequences of the VP4 (VP8*) gene were successfully obtained and were used for phylogenetic analysis. Analysis of the VP4 (VP8*) gene showed that all strains in this study were located in a subcluster of lineage $\mathrm{V}$ together with the LB1562/USA and KOL-53-09/India strains (99.7\% identity), which are separated from another subcluster that included strains from other parts of the world (Fig. 1). According to a study by Espinola et al. [26], 
Fig. 1. Nucleotide phylogenetic analysis of VP7 and VP4 partial gene sequences detected in this study and compared to reference strains. The evolutionary history was inferred by using the maximum likelihood method based on the Kimura 2-parameter model (1,000 iterations for bootstrapping). Phylogenetic analyses were conducted in MEGA6. Asterisks (*) indicate the strains sequenced in this study; HM34 ( $\ddagger)$ represents the strains HM10, HM28, HM29, HM34, HM39, HM40, and HM45; HM33 $(\dagger)$ represents the strains HM9, HM13, HM17, HM25, HM33, HM37, HM46, HM49, HM54, and HM63. Numbers in branches indicate the percentage of iterations corresponding to each branch. The scale bars indicate the nucleotide distance.

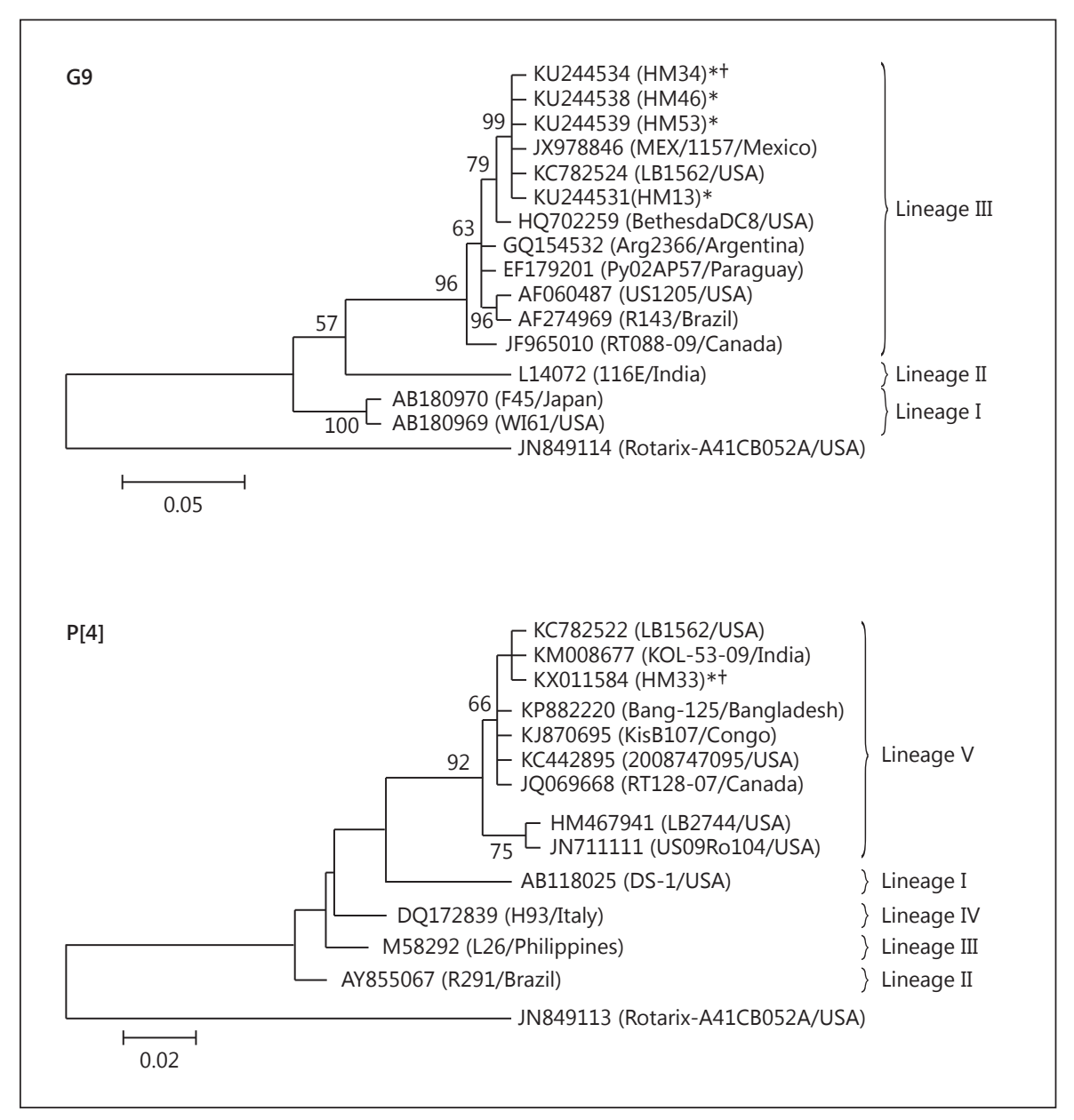

lineage V-grouped strains have been isolated worldwide from the early 1990s through to the present.

The partial deduced amino acid sequences of the VP7 protein were compared with human G9 sequences from GenBank. The sequence analysis included the antigenic regions A (87-101), B (142-152), C (208-221), E (189190) and F (233-242) [9]. Eight of the strains in this study had identical sequences, while strains HM46 and HM53 had 1 amino acid substitution at position $156(\mathrm{~A} \rightarrow \mathrm{T})$ and $241(\mathrm{~T} \rightarrow \mathrm{I})$, respectively (Fig. 2).

All of the deducted amino acid sequences of the VP7 gene in this study were very similar (identity rate 98.199.0\%) to strains US1205 and R143 (used as references for lineage III) and were clearly distinguished from lineages I (strains WI61 and F45) and II (116E) by specific amino acid differences in the antigenic regions $\mathrm{A}, \mathrm{B}$, and $\mathrm{C}$, which are the regions primarily responsible for determining the G serotype [27]. All strains in this study and the Mexican reference strain Mex1157 (G9P[4]) had an I at position 78 and 108, unlike the rest of the strains used for comparison, which contained a T. All of the strains had different amino acids in positions 208, 220, and 221 from the antigenic region $\mathrm{C}$ and in position 242 of region $\mathrm{F}$, compared to the vaccine strain Rotarix/G1P[8]/USA.

The strain Mex1157 was collected in a 2009-2010 outbreak that occurred in several states of Mexico, especially in Chiapas [13]. The strain LB1562, collected in 2010 in Long Beach, CA, USA, had a $100 \%$ identity with the partial VP7 gene of the strains isolated in Mexico during that same year [28] and with 8 strains collected during 2011 in the present report (represented by strain HM34 in Fig. 2). Hence, it is very likely that the strains detected in the present study are the same strain that was circulating during the 2009-2010 season, and that, over a 2-year period, accumulated the mutations identified in the sequences of strains HM46 and HM53.

The deduced amino acid sequences of the VP4 (VP8*) protein were compared with human $\mathrm{P}[4]$ sequences 


\begin{tabular}{|c|c|c|c|c|c|c|c|c|c|c|c|c|c|c|c|c|c|c|c|c|c|c|c|c|c|c|c|c|c|c|}
\hline Antigenic site & 1 & I & 1 & 1 & 1 & I & 1 & 1 & 1 & 1 & I & I & I & I & 1 & I & I & I & 1 & I & 1 & 1 & I & I & 1 & I & I & I & I & I \\
\hline AB180970 (F45/Japan) & . & . & & . & L & Q & $\mathrm{E}$ & . & . & . & & & . & . & . & & . & . & & . & . & . & & & . & . & . & . & . & . \\
\hline L14072 (116E/India) & . & $\mathrm{V}$ & & $\mathrm{T}$ & . & $\mathrm{Q}$ & $\mathrm{E}$ & . & I & G & & . & $\mathrm{F}$ & . & $\mathrm{v}$ & $\mathrm{N}$ & . & . & A & $\mathrm{N}$ & $\mathrm{s}$ & . & . & $\mathrm{T}$ & $\mathrm{N}$ & . & $\mathrm{N}$ & & $\mathrm{K}$ & $\mathrm{L}$ \\
\hline AF060487 (US1205/USA) & . & . & 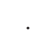 & . & . & Q & $\mathrm{E}$ & . & $\mathrm{T}$ & . & . & . & . & . & . & . & . & . & . & . & $\mathrm{s}$ & I & . & $\mathrm{T}$ & . & . & $\mathrm{N}$ & $\mathrm{K}$ & . & . \\
\hline AF274969 (R143/Brazil) & . & & . & . & . & Q & $\mathrm{E}$ & & $\mathrm{T}$ & . & & & . & . & . & . & . & . & I & . & $\mathrm{s}$ & I & & $\mathrm{T}$ & . & . & $\mathrm{N}$ & $\mathrm{K}$ & . & . \\
\hline KU244539 (HM53/Mexico)* & . & . & . & . & . & Q & $\mathrm{E}$ & I & $\mathrm{T}$ & . & . & I & . & . & . & . & . & . & . & . & $\mathrm{s}$ & I & . & $\mathrm{T}$ & . & I & $\mathrm{N}$ & $\mathrm{K}$ & & . \\
\hline KC782524 (LB1562/USA) & . & & . & . & & $\mathrm{Q}$ & $E$ & I & $\mathrm{T}$ & . & . & I & . & & . & . & . & . & . & & $\mathrm{s}$ & I & . & $\mathrm{T}$ & . & & $\mathrm{N}$ & $\mathrm{K}$ & . & \\
\hline JX978846 (Mex1157/Mexico) & . & . & . & . & . & $\mathrm{Q}$ & $\mathrm{E}$ & I & $\mathrm{T}$ & . & & I & . & . & . & . & . & . & . & . & $\mathrm{s}$ & I & . & $\mathrm{T}$ & . & . & $\mathrm{N}$ & $\mathrm{K}$ & . & . \\
\hline HQ702259 (BethesdaDC8/USA) & & & . & & . & Q & $\mathrm{E}$ & . & $\mathrm{T}$ & . & $\mathrm{L}$ & . & . & I & . & . & . & . & . & G & $\mathrm{s}$ & I & . & $\mathrm{T}$ & . & & $\mathrm{N}$ & $\mathrm{K}$ & & . \\
\hline EF179201 (Py02AP57/Paraguay) & & . & . & & . & $\mathrm{Q}$ & $\mathrm{E}$ & . & $\mathrm{T}$ & . & . & & . & . & . & . & . & . & . & . & $S$ & I & A & $\mathrm{T}$ & . & . & $\mathrm{N}$ & K & & . \\
\hline GQ154532 (Arg2366/Argentina) & & & $\mathrm{v}$ & & . & Q & $\mathrm{E}$ & . & $\mathrm{T}$ & . & . & . & . & . & . & . & . & & . & . & $\mathrm{s}$ & 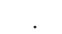 & . & $\mathrm{T}$ & . & . & $\mathrm{N}$ & $\mathrm{K}$ & & . \\
\hline JF965010 (RT088-09/Canada) & $\mathrm{F}$ & & & & & Q & $\mathrm{E}$ & . & $\mathrm{T}$ & . & . & . & . & & . & & & $\mathrm{K}$ & . & & $\mathrm{s}$ & I & . & $\mathrm{T}$ & & . & $\mathrm{N}$ & $\mathrm{K}$ & & . \\
\hline
\end{tabular}

Fig. 2. Partial amino acid sequence alignment of the VP7 gene of selected strains in this study. The accession numbers of the strains are shown to the left. Dots indicate similarity with strain WI61(AB180969) prototype sequence at that position. Antigenic sites are indicated above the position number in bold letters. As- terisks $\left(^{*}\right)$ indicate the strains detected in this study; HM34 ( $)$ represents the strains HM10, HM13, HM28, HM29, HM34, HM39, HM40, and HM45, which are identical in amino acid sequence.

\begin{tabular}{|c|c|c|c|c|c|c|c|c|c|c|c|c|c|c|}
\hline & & $\boldsymbol{\nabla}$ & & $\boldsymbol{\nabla}$ & $\boldsymbol{\nabla}$ & & & & & $\nabla$ & & & & \\
\hline & 32 & 35 & 51 & 55 & 60 & 87 & 89 & 99 & 111 & 120 & 130 & 133 & 149 & 150 \\
\hline KC782522 (LB1562/USA) & $\mathrm{N}$ & I & G & I & $\mathrm{T}$ & $\mathrm{N}$ & $\mathrm{D}$ & s & $\mathrm{H}$ & $\mathrm{v}$ & I & s & S & $\mathrm{D}$ \\
\hline KX011584 (HM33)*† & . & . & . & . & . & . & . & . & . & . & . & . & & . \\
\hline KM008677 (KOL-53-09/India) & . & . & . & . & . & . & . & . & . & . & . & & . & . \\
\hline KP882220 (Bang-125/Bangladesh) & . & $\mathrm{V}$ & . & . & . & . & . & . & . & . & . & . & & . \\
\hline KJ870695 (KisB107/Congo) & . & $\mathrm{v}$ & . & . & . & . & . & . & . & . & . & . & . & . \\
\hline KC442895 (2008747095/USA) & . & $\mathrm{v}$ & . & . & . & . & & . & . & . & . & . & & . \\
\hline JQ069668 (RT128-07/Canada) & & $\mathrm{v}$ & 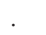 & . & . & . & . & . & . & . & . & . & . & . \\
\hline AB118025 (DS-1/USA) & $\mathrm{s}$ & $\mathrm{V}$ & . & . & 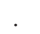 & . & $\mathrm{N}$ & $\mathrm{N}$ & . & I & $\mathrm{V}$ & $\mathrm{N}$ & G & $\mathrm{N}$ \\
\hline AY855067 (R291/Brazil) & . & 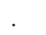 & & & I & . & . & . & . & I & & $\mathrm{N}$ & G & E \\
\hline M58292 (L26/Philippines) & . & & $\mathrm{R}$ & & . & . & . & . & $\mathrm{R}$ & I & & $\mathrm{N}$ & . & $\mathrm{N}$ \\
\hline DQ172839 (H93/Italy) & . & & 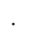 & $\mathrm{V}$ & . & . & . & . & . & I & . & $\mathrm{N}$ & & . \\
\hline HM467941 (LB2744/USA) & . & $\mathrm{V}$ & . & . & . & . & . & . & . & . & . & . & . & . \\
\hline JN711111 (US09Ro104/USA) & . & $\mathrm{V}$ & & . & . & $\mathrm{s}$ & & . & . & & $\mathrm{V}$ & & G & \\
\hline JN849113 (Rotarix G1P1A[8]/USA) & . & 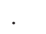 & D & . & . & . & $\mathrm{N}$ & . & . & M & $\mathrm{V}$ & D & $\mathrm{N}$ & $\mathrm{E}$ \\
\hline
\end{tabular}

Fig. 3. Partial amino acid sequence alignment of the VP4 gene of selected strains in this study. The accession numbers of the strains are shown to the left. Dots indicate similarity with strain LB1562/ USA (KC782522) sequence at that position. Antigenic sites are in- dicated $(\boldsymbol{\nabla})$ above the position number. Asterisks $\left(^{*}\right)$ indicate the strains detected in this study; HM33 $(\dagger)$ represents the strains HM9, HM13, HM17, HM25, HM33, HM37, HM46, HM49, HM54, and HM63, which are identical in amino acid sequence. from GenBank. The sequence analysis included the antigenic regions I35R44, I55D66, and V115G123 [29]. The amino acid sequences are shown in Figure 3. All samples sequenced for this study were $100 \%$ identical to each other and to strains LB1562/USA and KOL-53-09/ India. All of the sequences had different amino acid point substitutions with respect to the vaccine strain Rotarix/G1P[8]/USA, and only 1 of the substitutions (posi- tion $120, \mathrm{~V} \rightarrow \mathrm{M}$ ) corresponded to the antigenic region V115G123.

This is the first RVA G9P[4] genotyping report in the northwest region of Mexico. Our study is of particular importance, as the prevalence of RVA is based solely on diagnosis by antigen-detection immunoassay, and only random samples from selected states are genotyped by the Health Ministry. Hence, there is a need to increase 
surveillance for the predominant genotypes to oversee changes in circulating rotaviruses, especially in the vaccinated population. Moreover, the persistence of the G9P [4] genotype in the Northwestern Mexican population may be due to the high volume of migrant farm workers from Mexico and Central America who pass through the Sonora territory on their way to the USA. We emphasize the need for continuing surveillance to assess the suitability of current rotavirus vaccines.

\section{Acknowledgments}

This project was financed by CONACyT grant 202318. The authors are grateful to the patients and physicians of the Infectology Department of HIES for their valuable help in sample collection.

\section{Disclosure Statement}

The authors have no conflicts of interest to declare.

\section{References}

1 Parashar UD, Burton A, Lanata C, BoschiPinto C, Shibuya K, Steele D, Birmingham M, Glass RI: Global mortality associated with rotavirus disease among children in 2004. J Infect Dis 2009;200(suppl 1):S9-S15.

2 Tate JE, Burton AH, Boschi-Pinto C, Parashar UD; World Health Organization-Coordinated Global Rotavirus Surveillance Network: Global, regional, and national estimates of rotavirus mortality in children $<5$ years of age, 2000-2013. Clin Infect Dis 2016;62:S96-S105.

3 Matthijnssens J, Ciarlet M, McDonald, SM, Attoui H, Bányai K, Brister JR, Buesa J, Esona MD, Estes MK, Gentsch JR, Iturriza-Gómara M, Johne R, Kirkwood CD, Martella V, Mertens PP, Nakagomi O, Parreño V, Rahman M, Ruggeri FM, Saif LJ, Santos N, Steyer A, Taniguchi K, Patton JT, Desselberger U, Ranst MV: Uniformity of rotavirus strain nomenclature proposed by the Rotavirus Classification Working Group (RCWG). Arch Virol 2011;156:1397-1413.

4 Trojnar E, Sachsenröder J, Twardziok S, Reetz J, Otto PH, Johne R: Identification of an avian group A rotavirus containing a novel VP4 gene with a close relationship to those of mammalian rotaviruses. J Gen Virol 2013;94:136-142.

5 Bányai K, László B, Duque J, Steele AD, Nelson EAS, Gentsch JR, Parashar UD: Systematic review of regional and temporal trends in global rotavirus strain diversity in the pre rotavirus vaccine era: insights for understanding the impact of rotavirus vaccination programs. Vaccine 2012;30:A122-A130.

6 Matthijnssens J, Heylen E, Zeller M, Rahman M, Lemey P, van Ranst M: Phylodynamic analyses of rotavirus genotypes G9 and G12 underscore their potential for swift global spread. Mol Biol Evol 2010;27:24312436.

7 Yamamoto SP, Kaida A, Ono A, Kubo H, Iritani N: Detection and characterization of a human G9P [4] rotavirus strain in Japan. J Med Virol 2015;87:1311-1318.
8 Linhares AC, Stupka JA, Ciapponi A, Bardach AE, Glujovsky D, Aruj PK, Mazzoni A, Buendia JA, Rearte A, Lanzieri TM, OrtegaBarria E, Colindres R: Burden and typing of rotavirus group A in Latin America and the Caribbean: systematic review and metaanalysis. Rev Med Virol 2011;21:89-109.

9 Phan TG, Okitsu S, Maneekarn N, Ushijima $\mathrm{H}$ : Genetic heterogeneity, evolution and recombination in emerging G9 rotaviruses. Infect Genet Evol 2007;7:656-663.

10 Padilla-Noriega L, Méndez-Toss M, Menchaca G, Contreras JF, Romero-Guido P, Puerto FI, Guiscafré H, Mota F, Herrera I, Cedillo R, Muñoz O, Calva J, Guerrero MdL, Coulson BS, Greenberg HB, Lopez S, Arias $\mathrm{CF}$ : Antigenic and genomic diversity of human rotavirus VP4 in two consecutive epidemic seasons in Mexico. J Clin Microbiol 1998;36:1688-1692.

11 Rodríguez-Castillo A, Velasco-Villa A, Ramírez-González JE, Mayén-Pimentel E, Melo-Munguía M, Diaz de Jesús B, OliveraDíaz H, García-Lozano H: VP4 and VP7 genotyping by reverse transcription-PCR of human rotavirus in Mexican children with acute diarrhea. J Clin Microbiol 2000;38: 3876-3878.

12 González-Losa MDR, Rodríguez-Angulo E, Manzano-Cabrera L, Mejía-Cámara J, Puerto-Solís M: Detection of unusual strains of $\mathrm{RV}$ in patients with acute diarrhoea in Mexico. J Clin Virol 2005;32:325-328.

13 Quaye O, McDonald S, Esona MD, Lyde FC, Mijatovic-Rustempasic S, Roy S, Castro Banegas DJ, Mencos Quiñonez Y, Chinchilla BL, Gómez Santiago F, García Lozano H, Rey-Benito G, de Oliveira LH, Gentsch JR, Bowen MD: Rotavirus G9P [4] in 3 countries in Latin America, 2009-2010. Emerg Infect Dis 2013; 19:1332.

14 Gentsch JR, Glass RI, Woods P, Gouvea V, Gorziglia M, Flores, J, Das BK, Bhan MK: Identification of group A rotavirus gene 4 types by polymerase chain reaction. J Clin Microbiol 1992;30:1365-1373.
15 Gouvea V, Glass RI, Woods P, Taniguchi K, Clark HF, Forrester B, Fang ZY: Polymerase chain reaction amplification and typing of rotavirus nucleic acid from stool specimens. J Clin Microbiol 1990;28:276-282.

16 Iturriza-Gomara M, Kang G, Gray J: Rotavirus genotyping: keeping up with an evolving population of human rotaviruses. J Clin Virol 2004;31:259-265.

17 Maes P, Matthijnssens J, Rahman M, van Ranst M: RotaC: a web-based tool for the complete genome classification of group A rotaviruses. BMC Microbiol 2009;9:238.

18 Tamura K, Stetcher G, Peterson D, Filipski A, Kumar S: MEGA6: molecular evolutionary genetics analysis (MEGA) software version 6.0. Mol Biol Evol 2013;30:2725-2729.

19 Dóró R, Lázló B, Martella V, Leshem E, Gentsch J, Parashar U, Bányai K: Review of global rotavirus strain prevalence data from six years post vaccine licensure surveillance: is there evidence of strain selection from vaccine pressure? Infect Genet Evol 2014;28: 446-461.

20 Laird AR, Ibarra V, Ruiz-Palacios G, Guerrero ML, Glass RI, Gentsch JR: Unexpected detection of animal VP7 genes among common rotavirus strains isolated from children in Mexico. J Clin Microbiol 2003;41:44004403.

21 Yen C, Figueroa JR, Uribe ES, del CarmenHernández L, Tate JE, Parashar UD, Patel MM, López-Collado VR: Monovalent rotavirus vaccine provides protection against an emerging fully heterotypic G9P [4] rotavirus strain in Mexico. J Infect Dis 2011;204:783786.

22 Cao D, Santos N, Jones RW, Tatsumi M, Gentsch JR, Hoshino Y: The VP7 genes of two G9 rotaviruses isolated in 1980 from diarrheal stool samples collected in Washington, DC, are unique molecularly and serotypically. J Virol 2008;82:4175-4179. 
23 Ramachandran M, Kirkwood CD, Unicomb L, Cunliffe NA, Ward RL, Bhan MK, Clark HF, Glass RI, Gentsch JR: Molecular characterization of serotype G9 rotavirus strains from a global collection. Virology 2000;278: 436-444.

24 Martella V, Terio V, Arista S, Elia G, Corrente M, Madio A, Pratelli A, Tempesta M, Cirani A, Buonavoglia C: Nucleotide variation in the VP7 gene affects PCR genotyping of G9 rotaviruses identified in Italy. J Med Virol 2004;72:143-148.
25 Samajdar S, Ghosh S, Chawla-Sarkar M, Mitra U, Dutta P, Kobayashi N, Naik TN: Increase in prevalence of human group A rotavirus G9 strains as an important VP7 genotype among children in eastern India. J Clin Virol 2008;43:334-339.

26 Espinola EE, Amarilla A, Arbiza J, Parra GI: Sequence and phylogenetic analysis of the VP4 gene of human rotaviruses isolated in Paraguay. Arch Virol 2008;153:1067-1073.

27 Ramachandran M, Gentsch JR, Parashar UD, Jin S, Woods PA, Holmes JL, Kirkwood CD, Bishop RF, Greenberg HB, Urasawa S, Gerna G, Coulson BS, Taniguchi K, Bresee JS, Glass RI: Detection and characterization of novel rotavirus strains in the United States. J Clin Microbiol 1998;36:3223-3229.
28 Lewis J, Roy S, Esona MD, Mijatovic-Rustempasic S, Hardy C, Wang Y, Cortese M, Bowen MD: Full genome sequence of a reassortant human G9P [4] rotavirus strain. Genome Announ 2014;2:e01284-e01214.

29 Kovacs-Nolan J, Yoo D, Mine Y: Fine mapping of sequential neutralization epitopes on the subunit protein VP8 of human rotavirus. Biochem J 2003;15:269-275. 